\title{
Effectiveness of an integrated approach to reduce perinatal mortality: recent experiences from Matlab, Bangladesh
}

\author{
Anisur Rahman 1*, Allisyn Moran1, Jesmin Pervin, Aminur Rahman, Monjur Rahman', Sharifa Yeasmin, \\ Hosneara Begum', Harunor Rashid ${ }^{1}$, Mohammad Yunus ${ }^{1}$, Daniel Hruschka², Shams E Arifeen ${ }^{1}$, Peter K Streatfield ${ }^{1}$, \\ Lynn Sibley ${ }^{3}$, Abbas Bhuiya $^{1}$ and Marge Koblinsky ${ }^{4}$
}

\begin{abstract}
Background: Improving perinatal health is the key to achieving the Millennium Development Goal for child survival. Recently, several reviews suggest that scaling up available effective perinatal interventions in an integrated approach can substantially reduce the stillbirth and neonatal death rates worldwide. We evaluated the effect of packaged interventions given in pregnancy, delivery and post-partum periods through integration of communityand facility-based services on perinatal mortality.

Methods: This study took advantage of an ongoing health and demographic surveillance system (HDSS) and a new Maternal, Neonatal and Child Health (MNCH) Project initiated in 2007 in Matlab, Bangladesh in half (intervention area) of the HDSS area. In the other half, women received usual care through the government health system (comparison area). The MNCH Project strengthened ongoing maternal and child health services as well as added new services. The intervention followed a continuum of care model for pregnancy, intrapartum, and postnatal periods by improving established links between community- and facility-based services. With a separate prepost samples design, we compared the perinatal mortality rates between two periods-before (2005-2006) and after (2008-2009) implementation of MNCH interventions. We also evaluated the difference-of-differences in perinatal mortality between intervention and comparison areas.
\end{abstract}

Results: Antenatal coverage, facility delivery and cesarean section rates were significantly higher in the postintervention period in comparison with the period before intervention. In the intervention area, the odds of perinatal mortality decreased by $36 \%$ between the pre-intervention and post-intervention periods (odds ratio: 0.64; 95\% confidence intervals: $0.52-0.78$ ). The reduction in the intervention area was also significant relative to the reduction in the comparison area (OR 0.73, 95\% Cl: 0.56-0.95; $P=0.018$ ).

Conclusion: The continuum of care approach provided through the integration of service delivery modes decreased the perinatal mortality rate within a short period of time. Further testing of this model is warranted within the government health system in Bangladesh and other low-income countries.

\section{Background}

Reduction of perinatal mortality remains a major public health concern in low- and middle-income countries including Bangladesh [1-3]. Of approximately 8.8 million under-five child deaths, $40 \%$ are estimated to take place during the neonatal period (first 4 weeks of life) globally

\footnotetext{
* Correspondence: arahman@icddrb.org

'Centre for Reproductive Health, icddr,b, Mohakhali, Dhaka 1212, Bangladesh Full list of author information is available at the end of the article
}

[4]. In addition to neonatal deaths, about 2.6 million stillbirths (fetal deaths after 28 weeks of gestation) occur each year, which have similar consequences as neonatal death for family members, but remain largely unseen in official statistics [5-9]. Improvement of neonatal health, especially during the early neonatal period when about $60-80 \%$ of the deaths occur, is crucial to achieving the Millennium Development Goal (MDG) 4 for child survival [10]. Reviews suggest that scale up of the known

\section{C) Biomed Central}


evidence-based interventions following a life-cycle continuum (pregnancy, delivery and post-natal periods) and provided through integrated service delivery modes (family/community, outreach, and facility-based) may impact significantly on fetal and neonatal survival $[11,12]$.

Community-based trials with varying packages of maternal and neonatal interventions have been successful in reducing stillbirth and neonatal mortality in South Asia. Home-based interventions with outreach by trained community health workers in rural areas, including standardized assessment and treatment of neonatal infections, has reduced perinatal mortality in India [13] and neonatal deaths in Bangladesh [14]. However, a similar community-based package coupled with facilitation of referral to health facilities in Mirzapur, Bangladesh did not have any effect on perinatal survival [15]. Community-based studies which educated women through women's groups about effective newborn interventions using pictorial cards have reduced perinatal mortality in both Nepal [16] and India [17]. However, a study using similar interventions in northern Bangladesh did not observe any effect on perinatal mortality [18]. While communitybased interventions are promising, integrating these strategies with accessible quality services at facility levels is likely to have a much greater effect in improving perinatal health. As reported by Darmstadt et al. integrated community- and facility-based service delivery modes can potentially decrease neonatal mortality by about $40-70 \%[19,20]$. The objective of this study was to evaluate the effect of an integrated maternalnewborn health program using community- and facility-based approaches on perinatal mortality in a rural area in Matlab, Bangladesh.

\section{Methods}

\section{Study site}

The study was conducted in Matlab, a sub-district of Chandpur district, where the International Centre for Diarrhoeal Disease Research, Bangladesh (icddr, b) has implemented a health and demographic surveillance system (HDSS) in a population of about 220,000. Since 1966, community health research workers (CHRWs) have collected vital statistics such as marriage, birth, death, and migration. The HDSS area is divided into two parts: the icddr, b service area (SA) and the government SA. The icddr, b SA is divided into 4 administrative blocks, each serving a population of about 27,000 through a sub-center staffed by midwives that provide 24-h delivery care. Clinical activities in the sub-centers are supported by an icddr, b hospital in Matlab Township that offers basic obstetric care, staffed by medical doctors and nurses.
In the icddr, b SA, a maternal-child health and family planning (MCH-FP) program was initiated in 1977. The program started with distribution of family planning methods to women of reproductive age and provision of services for minor illnesses to women and children. Over the years, services were added to improve maternal and child health. In 1987, a safe motherhood program was introduced to increase the coverage of home births by midwives posted at the sub-center levels. A transport system was available for referral of women from subcenters to the Matlab Hospital. The home-birth strategy continued until 1996, after which it was redesigned for facility-based delivery care. Between 1996 and 2001, all four sub-centers of icddr, b SA were upgraded and equipped to perform basic obstetric care; home births with midwives were no longer offered.

In the government $\mathrm{SA}$, women receive pregnancy, delivery, and post-natal care from government health facilities. However, other non-formal health care providers (such as traditional birth attendants, village doctors) are active in the area. The lowest level of health care facility is the Health and Family Welfare Centre (union level sub-centre), which is equivalent to icddr, b sub-center, and provide antenatal and delivery care through a paramedic and a medical assistant. These sub-centers are linked with Upazila Hospital located at Matlab municipality where medical doctors, nurses and other support staff are available and provide essential obstetric care.

As both of the hospitals (icddr, b and Upazila) only provide basic obstetric care, woman who needs cesarean section has to travel to the neighboring districts-Chandpur and Narayanganj located in the south and the north of Matlab, respectively. The government district hospital and a growing number of private clinics provide such care. Women from icddr, b SA and from the south part of the government SA usually travel to Chandpur, which is about $20 \mathrm{~km}$ away from Matlab proper. The women from the northern part of the government service area usually travel to Narayanganj, which is $3-4 \mathrm{~h}$ journey by boat or by bus.

\section{Study design and population}

Initiated in 2007, the Maternal, Neonatal and Child Health $(\mathrm{MNCH})$ Project was embedded in the ongoing $\mathrm{MCH}-\mathrm{FP}$ Project. The MNCH Project implemented evidence-based maternal and neonatal interventions following the continuum of care approach from pregnancy to delivery to the postnatal period, and improving links between community- and facility-based service delivery modes.

The study employed a separate pre-post samples design which compared change in perinatal outcomes in the icddr, b SA and the government SA. Changes in 
study outcomes were assessed between two time periods-before (2005-2006) and after (2008-2009) implementation of $\mathrm{MNCH}$ intervention program in the icddr, b SA. We also used a difference-of- differences analysis to evaluate the reduction in perinatal mortality in the icddr, b SA (served as an intervention area) relative to the reduction in the government SA (served as a comparison area). We excluded outcome data from 2007, the year the interventions were rolled out.

The study population included pregnant women identified through routine bimonthly CHRWs' surveillance visits to households, and study participants were women who gave birth between 2005 and 2009 (excluding 2007). In total, 20,766 women were included in the analyses $(n=10,659$ from icddr, b SA and $n=10,107$ from government SA).

To evaluate the knowledge and practice on newborn care, we also conducted a baseline and an end-line survey in November 2006-February 2007 and April to June 2010 , respectively, on randomly selected women delivered in the last 1 year in both icddr, b SA and government SA. In total 4,704 women were interviewed from both areas.

\section{Interventions and process of implementation of study}

The MNCH Project aimed to increase facility-based delivery and to improve maternal, neonatal and child health. At the outset of the project, a needs assessment focusing on training, infrastructure, and administrative issues was conducted. Based on this assessment, priority areas were selected-including strengthening existing interventions under the existing $\mathrm{MCH}-\mathrm{FP}$ program and adding new interventions as needed. Figure 1 displays the full intervention package differentiating between the existing $\mathrm{MCH}-\mathrm{FP}$ interventions (before the present study) and new interventions using the model presented by Kerber et al. [12]. Interventions were described in two dimensions: the life cycle and mode of service delivery (family/household, outreach, facility). We also included a third dimension on quality assurance and management information system at all levels (Figure 1).

\section{Community level interventions}

In 2007, CHRWs were separated into surveillance and service CHRWs. The surveillance CHRWs were responsible for pregnancy identification and collection of vital event information including pregnancy outcomes. The service CHRWs were responsible for all curative and preventive care at community levels, including household visits.

Pregnant women were identified during routine bimonthly surveillance CHRWs' visits and confirmed by spot urine test. At 12-14 weeks of pregnancy, service CHRWs visited the pregnant woman at home, and if the woman consented to participate in the study, provided counseling on danger signs, referral and birth planning using a pictorial card. Service CHRWs also encouraged each woman to select a support person to assist her with labor and delivery, and counseled the woman and her family on the importance of attending four facilitybased antenatal care visits.

At weeks 32-34, a service CHRW visited the woman and her family for a second time to provide specific messages on birth planning, newborn care and to establish a birth team. During this visit, CHRWs encouraged pregnant women to attend a facility for delivery. After delivery, CHRWs conducted home-based postnatal visits within $24 \mathrm{~h}$ of delivery (for women who gave birth at home), and on days 3, 7, and 28 (for all women). During these postnatal visits, CHRWs identified danger signs using an algorithm based on the guidelines outlined in the WHO manual for child, neonatal and maternal health [21], and referred mother or neonate to the Matlab hospital if needed, provided counseling on newborn and maternal wellbeing, breastfeeding, and family planning.

Home-based Life Saving Skills (HBLSS), developed by the American College of Nurse-Midwives, was an important component of the intervention package [22]. HBLSS is a family- and community-focused, competency-based training for women and their identified support persons on prevention, first aid and referral for post-partum hemorrhage, prolonged labor and birth asphyxia [23]. The content is reinforced through a pictorial Take Action Card that is taken home for reference [24]. Each pregnant woman and her support person were encouraged to participate in 4 HBLSS sessions during pregnancy. These group-sessions were conducted by the service CHRWs at the respective CHRW's home.

In addition to the interventions, there were bi-weekly meetings at each sub-centre attended by CHRWs, midwives from the respective sub-centre and $\mathrm{MNCH}$ project staff to discuss problems identified at field and facility levels and to provide refresher trainings on the ongoing interventions.

\section{Facility level interventions}

Standard guidelines were developed and implemented for the management of maternal and newborn complications, including mouth-to-mouth and bag-and-mask ventilation to resuscitate babies with asphyxia. At both the icddr, b sub-center and hospital levels, providers' skills were strengthened on management of normal and complicated deliveries as well as management of newborn complications through a series of trainings conducted within icddr, b and outside involving tertiary care hospitals (Institute of Child and Maternal Health, Matuail, Dhaka; and Bangladesh Institute of Research and Rehabilitation in Diabetes, Endocrine and Metabolic Disorders Hospital, Dhaka, Bangladesh). 


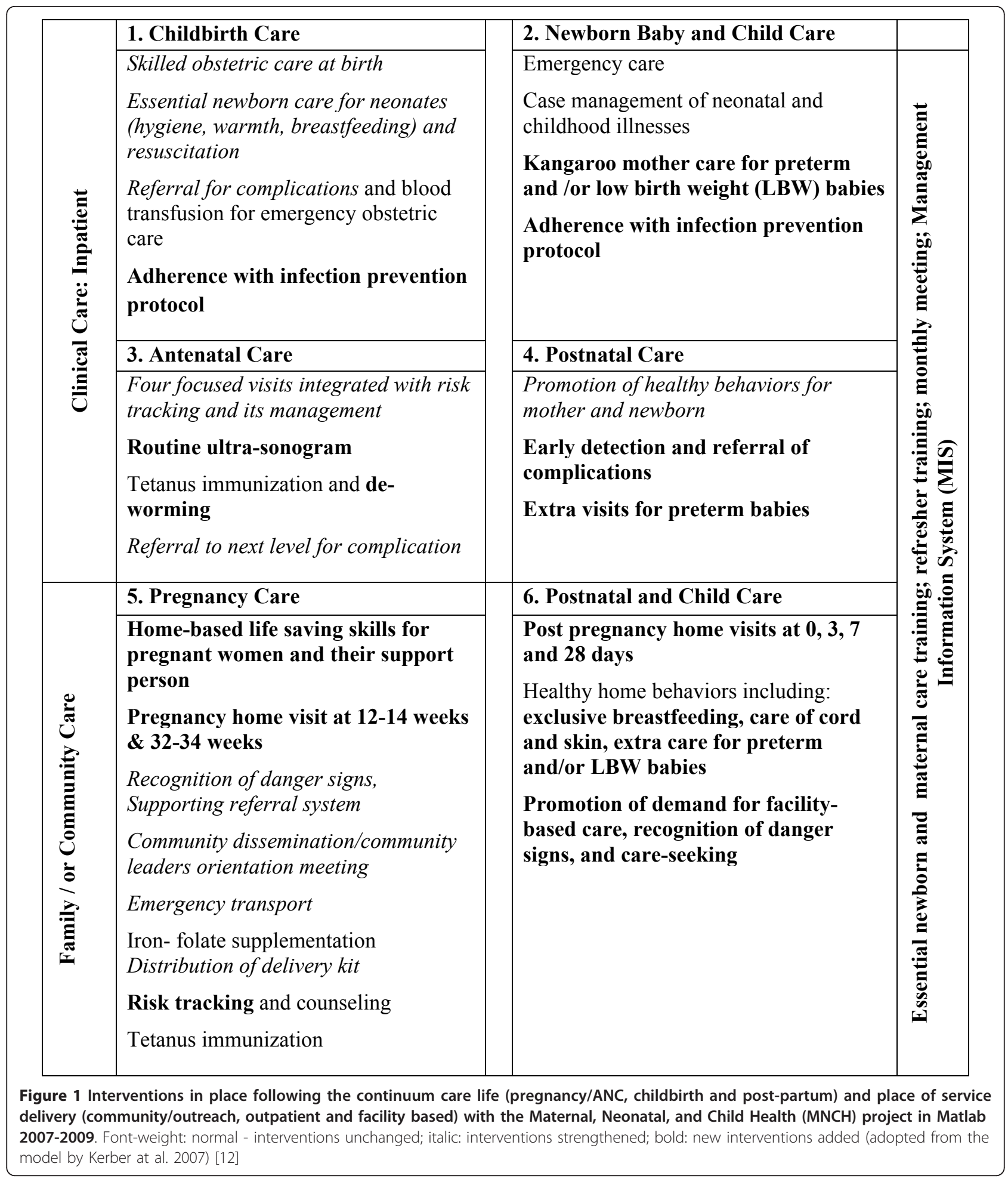

The MNCH project offered four focused ANC visits either at a sub-centre or at icddr, b Matlab Hospital covering physical examination, risk identification and management, and counseling including birth preparedness. All deliveries in icddr, $\mathrm{b}$ facilities were monitored by the partograph and active management of the third stage of labor using oxytocin was routinely practiced. Support persons were allowed in the delivery room, and women could select their labor position. Women requiring cesarean section were referred to the Chandpur 
district hospital or a private clinic where the $\mathrm{MNCH}$ Project had established lower fees for intervention area (icddr, b service area) patients. Referral transport was provided by the project. In addition the project constructed a Kangaroo Mother Care (KMC) unit adjacent to Matlab Hospital for care of low birth weight and/or premature babies.

At icddr, b Matlab hospital, services were further strengthened to provide magnesium sulfate for preeclampsia and eclampsia, assisted deliveries (with vacuum), manual removal of the placenta, blood transfusion, standardized management of post-date pregnancies through protocol, corticosteroid treatment for women with preterm labor, and antibiotic use with premature rupture of membranes.

In addition, quality assurance was in place with a checklist for ANC, infection prevention, delivery care, immediate newborn care and Kangaroo Mother Care activities at the facility level. The checklist was conducted bi-monthly by a medical officer, who was also part of the research team. Any discrepancy in service delivery observed was discussed with the health care provider and continually observed until corrected accordingly. The community level HBLSS sessions and CHRW pregnancy and postnatal home visits were also checked by the assigned paramedical staff for each intervention block. We also established perinatal audits in both hospital and community levels. To improve the quality of care, the factors related with administration, logistics and quality of care generated from the perinatal audits were discussed with all staff during the monthly meeting of the $\mathrm{MNCH}$ program. In addition a webbased hospital management system was in place that followed selected process and outcome indicators related with the project; this information guided the projects staff to strengthen the project efforts where gaps were noted.

\section{Care in the government service area}

The government of Bangladesh (GoB) took initiative to improve the development of human resources and infrastructure (through comprehensive emergency obstetric care, basic emergency obstetric care, and birthing centers) and to upgrade the skills of skilled birth attendants. However, the available services provided through facilities are not specified well. The survey reported that the important elements of antenatal care such as providing iron supplements, educating women on the signs of pregnancy complications, performing screening tests (including urine and blood tests), and measuring weight gain and blood pressure were not uniform at population level across different strata of the society [25]. Overall, the coverage of these interventions is also low. There are lack of routine ultrasound examination, risk tracking, management protocol for preterm delivery, post-term pregnancies, and thermal care of neonates immediate after delivery in the government health facilities. Considering the low coverage of ANC and skilled delivery practices, the GoB has started a new initiativeDemand Side Financing (DSF) in several Upazilas (subdistricts) all over the country. The government SA has been a part of this initiative since 2008. With this program women receive some incentives for ANC care and delivery by skilled personnel. In addition service providers also get remuneration for their efforts [26].

\section{Outcome and related data}

Outcome information was collected during bi-monthly surveillance CHRWs' visits, including pregnancy outcomes (spontaneous abortion, induced abortion, stillbirth, live birth) and survival during the neonatal period. Spontaneous abortion was defined as unintended loss of the fetus in the first 28 weeks of gestation, as determined by the last reported menstrual period. Induced abortion was defined as intended loss of fetus in the first 28 weeks of gestation. Stillbirth was defined as birth of a dead fetus after 28 weeks of gestation. Live birth was defined as birth of a fetus with any sign of viability. Neonatal death was defined as the death of a liveborn baby before 28 days of age. Early neonatal death was defined as death of neonates within 7 days of birth of a live-born baby. Perinatal death was defined as fetal (stillbirth) or early neonatal death. For each woman, delivery information such as place of delivery and type of delivery was also collected.

Information on cause of death was collected using the verbal autopsy method. Using a modified structured questionnaire developed by the World Health Organization [27], interviews were conducted with the caretakers/relatives who had lived with the infant in the same household during the terminal stages of illness and death of the infant. A physician reviewed each verbal autopsy form and filled out death certificates using the International Classification of Diseases version 10 (ICD10) codes, with notes to support the diagnosis.

Detailed information on women's age, parity, education, and household assets were collected from the HDSS databases and confirmed during interviews with study participants. Parity was defined as number of live or dead children before the current pregnancy. Educational status was assessed as number of years completed at school. Economic status was assessed by generating scores through principal-components analysis based on household assets, housing structure, land occupation, and income. These scores were then indexed into quintiles, where 1 represented the poorest and 5 the richest [28]. Last menstrual period date was determined by recall during the pregnancy-identification interview at 
the monthly household visits. Gestational age at pregnancy outcome was measured by subtracting the last menstrual period date from date of pregnancy outcome and was expressed in weeks.

\section{Statistical analysis}

Perinatal mortality, before and after the intervention, was analyzed using logistic regression in both icddr, b and government SA. The period before intervention (2005-2006) was used as the reference and associations were presented using odds ratios with their $95 \%$ confidence intervals. We also determined the difference-ofdifferences in perinatal mortality before and after the intervention between the icddr, b SA and government SA. We coded the time period as before $=0$ and after $=$ 1 , and the area as government SA (comparison) $=0$ and icddr, b SA (intervention) $=1$, and made an interaction term (time $\times$ area). The time, area and interaction term were entered in the logistic regression model. The alpha-value for the interaction term was set at 0.05 to indicate whether the reductions between two areas were statistically different. We also, divided the study area according to geographic importance into north and south, and determined odds of perinatal mortality between two time periods.

Background characteristics were evaluated with outcome variables and association determined by chisquare, analysis of variances, the Wald test, or by nonparametric test depending on the type of data being analyzed. Any socio-demographic characteristics associated with outcome variables at $P<0.20$ significance level were included in the logistic regression model for adjustment.

\section{Ethical considerations}

The study strengthened ongoing maternal and child health services and added evidence-based interventions at both community and facility levels. All women from icddr, b SA gave consent for participation in the $\mathrm{MNCH}$ study. In addition we also used routine data collected by the ongoing HDSS. This study was approved by the Research and Ethical Review Committees of International Centre for Diarrhoeal Disease Research, Bangladesh.

\section{Results}

Of the 10,659 births included in the study from the icddr, b SA, 10,412 resulted in live births (97.7\%), 247 resulted in stillbirths (23/1000 births) and 178 resulted in early neonatal deaths (17/1000 live births). In the government SA, of the 10,107 births, 9,793 resulted in live births (96.9\%), 314 resulted in stillbirths $(31 / 1000$ births), and 264 resulted in early neonatal deaths (27/ 1000 live births).
The background characteristics of the study participants before and after the intervention in both icddr, $b$ and government SAs are presented in Table 1. The socio-demographic characteristics, although significantly different between the two periods, were more or less similar in two areas. The proportion of preterm births (birth before 37-week gestation) in post-intervention period was significantly lower compared with pre-intervention period in both areas (Table 1).

The majority of women in the icddr, b SA were exposed to the $\mathrm{MNCH}$ interventions (Table 2). About $94 \%$ of women received home visits during early pregnancy (gestational week 12-14), 77\% during late pregnancy (gestational week 32-34). In the icddr, b SA, ANC visits were almost universal ( $78 \%$ of women received 3 or more ANC) during the intervention period in comparison with the pre -intervention period (38\%). Although statistically significant, the increase in ANC care was not pronounced in the government SA between two periods of observations. Marked increase in facility deliveries (from $55 \%$ to $72 \%$ in icddr, b SA, and from $13 \%$ to $22 \%$ in the government SA) and cesarean section rates (from $8 \%$ to $16 \%$ in icddr, b SA, and from $5 \%$ to $10 \%$ in the government SA) were observed between the two periods in both areas (Table 2).

High risk practices such as early bathing and late initiation of breast feeding were significantly different between the base-line and end-line periods in both icddr, b and government SA. Knowledge on newborn care practices also increased, however the changes were more pronounced in the icddr, b SA (Table 3).

Women's age, parity, education, asset index, and gestational age were associated with perinatal mortality in both areas (Table 4). Antenatal care coverage was significantly associated with perinatal mortality in the icddr, b SA but not in the government SA (Table 4).

Perinatal mortality decreased from $48 / 1000$ births to $32 / 1000$ births, respectively before and after the interventions in the icddr, b SA (Figure 2). The initial reduction of perinatal mortality in 2007 reflected the improvement of knowledge and skills of health care providers and initiation of evidence based practices at facility levels in a short period of time. There was almost no change in mortality in the government SA. The adjusted odds of perinatal mortality after the intervention was 36\% lower (OR: 0.64; 95\% CI: 0.52-0.78) compared with the rate before the intervention period (Table 5) in the intervention area (icddr, b SA). In the same area, when we stratified the analyses by place of delivery we found the odds of perinatal mortality (adjusted for women's age, parity, education and asset index) at icddr, b facility, home and other facilities were 0.69 (95\% CI: 0.50-0.95), 0.75 (95\% CI: $0.53-1.08$ ) and 0.35 (95\% CI: 0.23-0.52), respectively in the post-intervention period in 
Table 1 Background Characteristics of Study Women Before (2005-2006) and After (2008-2009) Intervention Implementation by Service Area, Matlab, Bangladesh

\begin{tabular}{|c|c|c|c|c|c|c|}
\hline \multirow[t]{3}{*}{ Variables* } & \multicolumn{3}{|c|}{ icddr, b Service Area } & \multicolumn{3}{|c|}{ Government Service Area } \\
\hline & \multirow{2}{*}{$\begin{array}{l}\text { Before } \\
\mathrm{N}(\%)\end{array}$} & \multirow{2}{*}{$\begin{array}{l}\text { After } \\
\mathrm{N}(\%)\end{array}$} & \multirow[t]{2}{*}{$P$-value } & \multirow{2}{*}{$\frac{\text { Before }}{\mathrm{N}(\%)}$} & \multirow{2}{*}{$\begin{array}{l}\text { After } \\
\mathrm{N}(\%)\end{array}$} & \multirow[t]{2}{*}{$P$-value } \\
\hline & & & & & & \\
\hline \multicolumn{7}{|l|}{ Age(years) } \\
\hline$<20$ & $749(14.0)$ & $778(14.7)$ & 0.015 & $703(13.3)$ & $563(11.7)$ & 0.019 \\
\hline $20-24$ & $1742(32.5)$ & $1755(33.1)$ & & $1691(32.0)$ & $1633(33.9)$ & \\
\hline $25-34$ & $2285(42.7)$ & $2297(43.3)$ & & $2358(44.6)$ & $2095(43.5)$ & \\
\hline$>=35$ & $578(10.8)$ & $475(9.0)$ & & $539(10.2)$ & $525(10.8)$ & \\
\hline Mean (SD+) age in year & $26.5(6)$ & $26.2(6)$ & & $26.5(6)$ & $26.7(6)$ & \\
\hline \multicolumn{7}{|l|}{ Parity } \\
\hline 0 & 1997 (37.3) & $2058(38.7)$ & $<0.001$ & $1840(34.8)$ & $1761(36.6)$ & 0.001 \\
\hline $1-2$ & $2524(41.1)$ & $2612(49.3)$ & & $2389(45.2)$ & $2226(46.2)$ & \\
\hline$>=3$ & 833 (15.6) & $634(12.0)$ & & $1062(20.1)$ & $829(17.2)$ & \\
\hline \multicolumn{7}{|l|}{ Asset index } \\
\hline 1 & $843(15.7)$ & $821(15.5)$ & 0.244 & $888(16.8)$ & $749(15.6)$ & $<0.001$ \\
\hline 2 & $927(17.3)$ & $904(17.0)$ & & $1037(19.6)$ & $805(16.7)$ & \\
\hline 3 & $1108(20.7)$ & $1070(20.2)$ & & $1033(19.5)$ & $1100(23.0)$ & \\
\hline 4 & $1227(22.9)$ & $1171(22.1)$ & & $1214(22.9)$ & $1092(22.7)$ & \\
\hline 5 & $1249(23.3)$ & $1339(25.2)$ & & $1119(21.1)$ & $1060(22.0)$ & \\
\hline \multicolumn{7}{|l|}{ Education (years) } \\
\hline No education & $1075(20.1)$ & $1007(19.0)$ & 0.188 & $1036(19.6)$ & $1313(27.3)$ & $<0.001$ \\
\hline Primary & $1384(25.8)$ & $1440(27.1)$ & & $1559(29.5)$ & $1396(29.0)$ & \\
\hline Secondary or above & $2895(54.1)$ & $2858(53.9)$ & & $2696(51.0)$ & $2107(43.8)$ & \\
\hline \multicolumn{7}{|l|}{ Gestational age (weeks) } \\
\hline$<37$ & $897(16.8)$ & $650(12.3)$ & $<0.001$ & $905(17.1)$ & $714(14.8)$ & $<0.001$ \\
\hline$>=37$ & $4457(83.2)$ & $4655(87.3)$ & & $4386(82.9)$ & $4102(85.2)$ & \\
\hline Mean (SD+) gestational age in weeks & $38.8(2.6)$ & $39.1(2.4)$ & & $38.7(2.5)$ & $39.0(2.5)$ & \\
\hline
\end{tabular}

${ }^{*}$ All are presented in percent unless stated

†SD: standard deviation

comparison to the odds of perinatal deaths among women delivered during the pre-intervention period. The perinatal mortality rates were similar in both periods in the government SA (Table 5).

We observed significant interaction between area of intervention and time-period $(P=0.018)$. There was $27 \%$ relative reduction in the odds of perinatal mortality in icddr, b SA compared to the reduction observed in the government SA (OR 0.73, 95\% CI: 0.56-0.95).

When we divided the population in different groups based on geographic location, we also observed similar trends in odds of perinatal mortality. In the icddr, b SA, the odds of perinatal mortality were 0.54 (95\% CI: 0.39 , 0.74 ) and 0.69 (95\% CI:0.54, 0.89), respectively, in north and south after the intervention in comparison to the period before. The similar figures in north and south part of the government SA were 0.91 (95\% CI: 0.70, 1.18 ) and 0.90 (95\% CI: 0.72, 1.13), respectively.
Birth asphyxia, prematurity, and infections were the leading causes of death as determined by verbal autopsies in both areas. We observed marked decrease in deaths related with birth asphyxia and infections in the icddr, b area (Table 6).

\section{Discussion}

Perinatal mortality remains an important public health issue in Bangladesh and other low-income settings. We show that an integrated intervention package across the continuum of care and provided at all levels of the service delivery system-home, out-reach clinic and facility level was associated with a $36 \%$ reduction in perinatal mortality. This finding has public health significance not only as a first, in terms of provision of an integrated package at all levels of service delivery, but also considering the observed effect in an area with a relatively low rate of perinatal mortality, and achieved in a short 
Table 2 Coverage of Selected Indicators Before (2005-2006) and After (2008-2009) Intervention Implementation by Service Area, Matlab, Bangladesh

\begin{tabular}{|c|c|c|c|c|c|c|}
\hline \multirow[t]{3}{*}{ Variable Name } & \multicolumn{3}{|c|}{ icddr, b Service Area } & \multicolumn{3}{|c|}{ Government Service Area } \\
\hline & Before & After & $P$-value & Before & After & $P$-value \\
\hline & Count (\%) & Count (\%) & & Count (\%) & Count (\%) & \\
\hline \multicolumn{7}{|c|}{ 1st Pregnancy Home visit (12-14 weeks) } \\
\hline No & $\mathrm{N} / \mathrm{A}$ & $305(5.7)$ & $N / A^{*}$ & $\mathrm{~N} / \mathrm{A}$ & N/A & $\mathrm{N} / \mathrm{A}$ \\
\hline Yes & N/A & $5000(94.3)$ & & $\mathrm{N} / \mathrm{A}$ & $\mathrm{N} / \mathrm{A}$ & \\
\hline \multicolumn{7}{|c|}{ 2nd Pregnancy Home visit (32-34 weeks) } \\
\hline No & N/A & $1236(23.3)$ & NA & $\mathrm{N} / \mathrm{A}$ & N/A & N/A \\
\hline Yes & N/A & $4069(76.7)$ & & $\mathrm{N} / \mathrm{A}$ & $\mathrm{N} / \mathrm{A}$ & \\
\hline \multicolumn{7}{|l|}{ PNC Home visits } \\
\hline No & N/A & $964(18.2)$ & N/A & N/A & N/A & N/A \\
\hline Yes & N/A & $4341(81.8)$ & & N/A & $\mathrm{N} / \mathrm{A}$ & \\
\hline \multicolumn{7}{|l|}{ HBLSS sessions } \\
\hline 0 & N/A & 415 (7.8) & N/A & $\mathrm{N} / \mathrm{A}$ & $\mathrm{N} / \mathrm{A}$ & N/A \\
\hline 1 & N/A & $271(5.1)$ & & $\mathrm{N} / \mathrm{A}$ & N/A & \\
\hline 2 & N/A & $451(8.5)$ & & $\mathrm{N} / \mathrm{A}$ & N/A & \\
\hline$>=3$ & $\mathrm{~N} / \mathrm{A}$ & 4115 (78.7) & & $\mathrm{N} / \mathrm{A}$ & $\mathrm{N} / \mathrm{A}$ & \\
\hline \multicolumn{7}{|l|}{ Facility ANC visit } \\
\hline 0 & $245(4.5)$ & $225(4.2)$ & $<0.001$ & $834(15.7)$ & 760 (15.6) & 0.005 \\
\hline 1 & $810(15.1)$ & $327(6.2)$ & & $2134(40.3)$ & $1782(37.0)$ & \\
\hline 2 & $2276(42.5)$ & 616 (11.6) & & $1984(37.5)$ & $1912(39.7)$ & \\
\hline$>=3$ & $2023(37.8)$ & 4137 (78.0) & & $362(7.5)$ & $362(7.5)$ & \\
\hline \multicolumn{7}{|l|}{ Place of delivery } \\
\hline Home & $2425(45.3)$ & $1465(27.6)$ & $<0.001$ & $4583(86.6)$ & $3717(78.2)$ & $<0.001$ \\
\hline Facility delivery & $2929(54.7)$ & 3840 (72.4) & & $708(13.4)$ & $1034(21.8)$ & \\
\hline \multicolumn{7}{|l|}{ Delivery type } \\
\hline Vaginal & 4889 (91.2) & $4466(84.2)$ & $<0.001$ & $5009(94.7)$ & $4329(89.9)$ & $<0.001$ \\
\hline Cesarean & $418(7.8)$ & 839 (15.8) & & $282(5.3)$ & $487(10.1)$ & \\
\hline
\end{tabular}

N/A: not application; PNC: postnatal care; HBLSS: home-based live saving skills; ANC: antenatal care

timeframe (a 2-3 year frame). Services were delivered at home/outreach clinics by CHRWs, at sub-centers by midwives and at hospital level mainly by midwives with support from medical officers with the possibility of referral but without the presence of specialists in obstetrics or neonatology.

The present study has several strengths. In addition to its large sample size, it involved continuous data collection over a 2 year period which diminishes the effects of seasonal variation on perinatal mortality. A separate group of CHRWs recorded both stillbirth and early neonatal death to prevent misclassification of outcomes. Relevant socio-demographic information serves as a statistical control on confounding. Moreover, the use of pre-post measurements and a comparison area as well as the existence of perinatal mortality data for numerous years prior to intervention provide important checks on internal validity.
However, the study results should be interpreted cautiously. As the intervention included integrated service delivery at multiple levels and also implemented evidence-based interventions, a randomized trial was not feasible. The baseline differences in ANC coverage, facility delivery, and cesarean section rates between the two areas limit the comparability between areas after implementation of the intervention. This difficulty in comparability between Matlab study areas at baseline in determining the final outcome has also been noted in other studies [29]. This raises several potential questions to the study finding's validity, some of which can be addressed by examining longer term trends in perinatal mortality. First, the observed effect of interventions on perinatal mortality may have resulted from a natural decrease over the time period of the study. However, we did not observe any change in perinatal mortality in the 2 years prior to the initiation of the $\mathrm{MNCH}$ project in 
Table 3 Immediate Newborn Care Practices and Knowledge of Newborn Danger Signs Before (2005-2006) and After (2008-2009) Intervention Implementation by Service Area, Matlab, Bangladesh

\begin{tabular}{|c|c|c|c|c|c|c|}
\hline & \multicolumn{3}{|l|}{ icddr, b service area } & \multicolumn{3}{|c|}{ Government service area } \\
\hline & $\begin{array}{l}\text { Baseline }(n=1211) \\
(\%)\end{array}$ & $\begin{array}{l}\text { End-line }(n=1153) \\
(\%)\end{array}$ & $P$-value & $\begin{array}{l}\text { Baseline }(n=1196) \\
(\%)\end{array}$ & $\begin{array}{l}\text { End-line }(n=1144) \\
(\%)\end{array}$ & $P$-value \\
\hline \multicolumn{7}{|l|}{ Newborn care practice } \\
\hline \multicolumn{7}{|l|}{ Timing of first newborn bath } \\
\hline$<1$ day & 29.7 & 4.1 & \multirow[t]{5}{*}{$<0.001$} & 43.7 & 23.6 & \multirow[t]{5}{*}{$<0.001$} \\
\hline 1 day & 8.8 & 2.0 & & 6.7 & 6.8 & \\
\hline 2 days & 14.2 & 8.1 & & 7.0 & 11.2 & \\
\hline$>=3$ days & 45.2 & 84.6 & & 41.3 & 56.1 & \\
\hline Don't remember & 2.1 & 1.2 & & $\overline{1.3}$ & 2.3 & \\
\hline \multicolumn{7}{|l|}{ Breastfeeding practice } \\
\hline \multicolumn{7}{|l|}{ Colostrums as first food } \\
\hline Yes & 82.5 & 96.1 & \multirow[t]{2}{*}{$<0.001$} & 57.8 & 75.3 & \multirow[t]{2}{*}{$<0.001$} \\
\hline No & 17.5 & 3.9 & & 42.2 & 24.7 & \\
\hline \multicolumn{7}{|l|}{ Timing of breastfeeding after birth } \\
\hline$<30 \min$ & 60.9 & 80.9 & \multirow[t]{3}{*}{$<0.001$} & 45.8 & 58.1 & \multirow[t]{3}{*}{$<0.001$} \\
\hline $30-59 \min$ & 21.0 & 6.7 & & 23.4 & 20.3 & \\
\hline$>=60 \mathrm{~min}$ & 18.2 & 12.4 & & 30.8 & 21.7 & \\
\hline \multicolumn{7}{|c|}{ Knowledge of danger sign for newborn } \\
\hline Difficult or fast breathing & 90.4 & 91.2 & 0.26 & 82.4 & 81.5 & 0.28 \\
\hline Poor sucking or feeding & 20.8 & 31.7 & $<0.001$ & 12.5 & 9.8 & 0.02 \\
\hline Yellow coloration skin/eye & 41.0 & 29.0 & $<0.001$ & 34.4 & 28.8 & 0.002 \\
\hline $\begin{array}{l}\text { Pus discharge from } \\
\text { umbilical cord }\end{array}$ & 7.9 & 44.3 & $<0.001$ & 3.8 & 4.4 & 0.26 \\
\hline Pus discharge from eyes & 2.7 & 25.2 & $<0.001$ & 0.8 & 1.0 & 0.37 \\
\hline Very small baby & 4.6 & 15.2 & $<0.001$ & 1.8 & 1.8 & 0.55 \\
\hline Convulsion & 33.9 & 49.0 & $<0.001$ & 17.1 & 20.8 & 0.01 \\
\hline Lethargy/unconsciousness & 1.7 & 2.8 & 0.05 & 0.7 & 0.8 & 0.46 \\
\hline None of above/others & 2.6 & 1.4 & 0.02 & 6.4 & 7.5 & 0.17 \\
\hline
\end{tabular}

either the icddr, b SA or government SA. Once the project began, perinatal mortality declined sharply (Figure 2). When we divided the study site into several areas with physical importance (north and south), we also observed similar pattern of perinatal mortality before and after the intervention periods. Furthermore, in a previous study in the same area it was reported that the decline in stillbirth and neonatal deaths was about $24 \%$ and $39 \%$, respectively over a period of 28 years (19752002) [30]. In the present study, a similar reduction in perinatal mortality was achieved in a 2 -year period. The temporal specificity and magnitude of the change in addition to the lack of change in the government SA, strongly suggest that the decrease in perinatal mortality in the icddr, b SA did occur due to the new initiative.

Notably, in the government SA, there was no decrease in perinatal mortality during the post-intervention follow-up period despite the substantial increase in positive care seeking behaviors. This change in care seeking may be explained by implementation of demand-side financing initiated in 2008 in the government SA only that offered incentives for ANC care (US\$ 1.0 for each ANC visit) and facility delivery (US\$ 7.7 for each delivery). In addition, a lump-sum of US\$ 93.0 is offered to the public or private facility that performs a cesarean section if needed [26]. That there was no impact on perinatal mortality with this initiative warrants further exploration.

The $\mathrm{MNCH}$ intervention package stressed intensive preventive community-work coupled with improved quality of facility care and strengthening linkages between community and facility care. The study achieved high coverage of key process indicators such as pregnancy home visits, HBLSS sessions for pregnant women and their support persons, and immediate home-based postnatal care. The program was also successful at creating demand for key facility-based interventions through community-based activities, improving 
Table 4 Association of Background Characteristics with Perinatal Mortality by Service Area in Matlab, Bangladesh

\begin{tabular}{|c|c|c|}
\hline \multirow[t]{2}{*}{ Variables } & icddr, b Service Area & \multirow{2}{*}{$\begin{array}{l}\text { Government Service Area } \\
\text { Odds ratio ( } 95 \% \text { confidence interval) }\end{array}$} \\
\hline & Odds ratio ( $95 \%$ confidence interval) & \\
\hline \multicolumn{3}{|l|}{ Age in years } \\
\hline$<20$ & $1.12(0.81-1.54)$ & $0.94(0.71-1.24)$ \\
\hline $20-24^{*}$ & 1.00 & 1.00 \\
\hline $25-34$ & $1.14(0.90-1.44)$ & $0.84(0.69-1.02)$ \\
\hline$>=35$ & $2.05(1.52-2.78)$ & $1.52(1.17-1.97)$ \\
\hline \multicolumn{3}{|l|}{ Parity } \\
\hline $0^{*}$ & 1 & 1 \\
\hline $1-2$ & $052(0.42-0.64)$ & $0.36(0.29-0.43)$ \\
\hline$>=3$ & $0.66(0.49-0.90)$ & $0.53(0.42-0.67)$ \\
\hline \multicolumn{3}{|l|}{ Asset index } \\
\hline 1 Poorest & $1.34(0.98-1.84)$ & $1.33(1.01-1.74)$ \\
\hline 2 & $1.15(0.83-1.58)$ & $0.96(0.72-1.27)$ \\
\hline 3 & $1.30(0.96-1.74)$ & $1.23(0.95-1.59)$ \\
\hline 4 & $1.18(0.88-1.59)$ & $1.07(0.82-1.38)$ \\
\hline 5 Richest* & 1.00 & 1.00 \\
\hline \multicolumn{3}{|l|}{ Education in year } \\
\hline 0 & $1.59(1.26-2.01)$ & $1.40(1.14-1.71)$ \\
\hline $1-5$ & $1.06(0.83-1.35)$ & $1.04(0.85-1.28)$ \\
\hline$>5^{*}$ & 1.00 & 1.00 \\
\hline \multicolumn{3}{|l|}{ Gestation age in weeks } \\
\hline$<37$ & $4.87(3.98-5.95)$ & $3.37(2.82-4.03)$ \\
\hline$>=37^{*}$ & 1.00 & 1.00 \\
\hline \multicolumn{3}{|c|}{ No. of antenatal care visits } \\
\hline$=<1$ & $3.03(2.37-3.90)$ & $1.19(0.83-1.71)$ \\
\hline 2 & $2.33(1.86-2.92)$ & $1.15(0.79-1.65)$ \\
\hline$>=3^{*}$ & 1.00 & 1.00 \\
\hline \multicolumn{3}{|l|}{ Delivery Place } \\
\hline Home & $0.90(0.73-1.10)$ & $0.43(0.36-0.52)$ \\
\hline Facility* & 1.00 & 1.00 \\
\hline \multicolumn{3}{|l|}{ Type of delivery } \\
\hline Cesarean section & $1.05(0.77-1.43)$ & $1.13(0.84-1.53)$ \\
\hline Vaginal * & 1.00 & 1.00 \\
\hline
\end{tabular}

*reference category

knowledge of danger signs, and recognition and referral (ANC coverage, facility delivery). That facility-based delivery increased from $48 \%$ to $72 \%$ is an encouraging achievement in a country where only $21 \%$ of women give birth in a facility nationwide [31].

The $\mathrm{MNCH}$ program implemented interventions known to improve perinatal health. Earlier studies had demonstrated the association of improved perinatal health with ANC [32] and birth-preparedness [33,34]. However, we didn't observe any association between ANC and perinatal mortality in the government SA, which probably reflects absence of effective linking between continuum of health system delivery modes and also lack of quality of services offered. In the icddr, $\mathrm{b}$ area, interventions during the intra-partum period such as prophylactic steroid use in preterm labor [35], antibiotic use for preterm rupture of membrane [36], planned cesarean section for breech, emergency obstetric care including cesarean section, and also induction of post-term pregnancy [37] have proved efficacious in improving perinatal health. Post-natal interventions such as facility-based Kangaroo Mother Care [38,39], early breastfeeding [40], and immediate postnatal visits for home births [41] have reported improvements in neonatal survival. Taken together, the decreased perinatal mortality in this study is likely attributed to the positive 


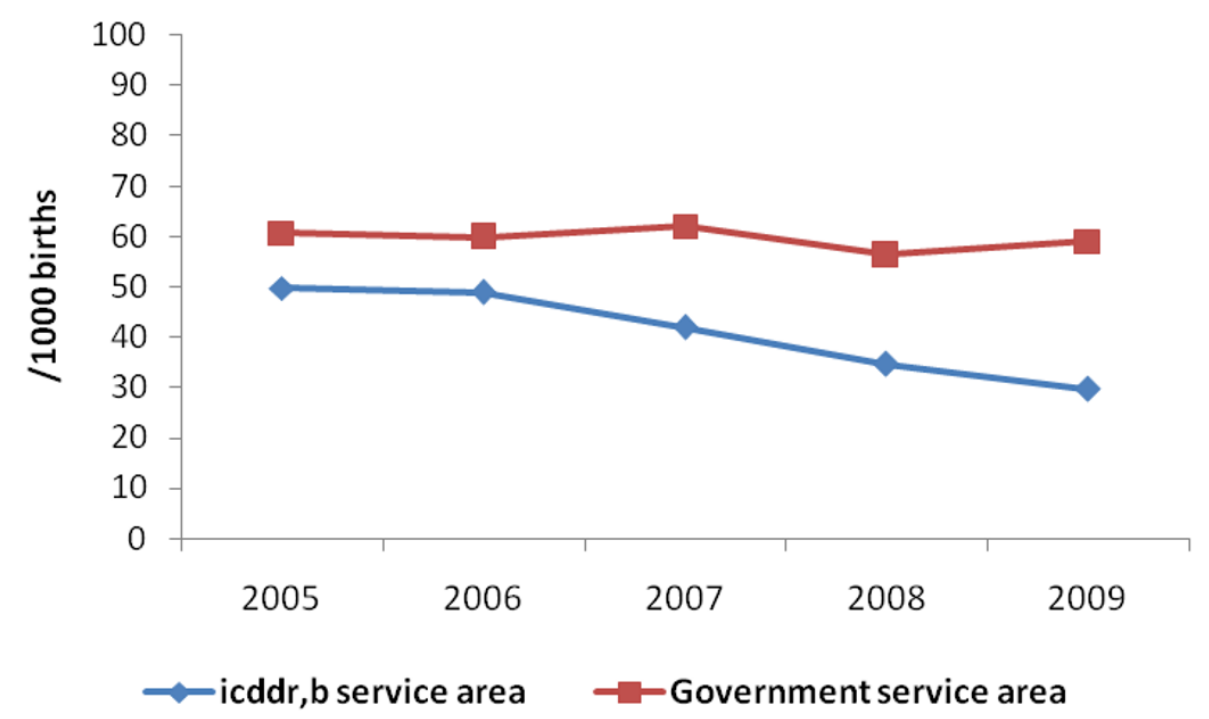

Figure 2 Perinatal Mortality Rate by Year in the Study Area 2005-2009 in Matlab, Bangladesh.

changes in care seeking behavior plus the availability of high quality services at community and basic emergency obstetric care levels (sub-centre and Matlab Hospital). Although improvement of quality of care was not undertaken in comprehensive emergency obstetric care facilities (these same facilities were used by both the icddr, b and government SA women), the MNCH program did improve the referral system to ensure timely response at district level (comprehensive emergency obstetric care) facilities.

There is a paucity of studies evaluating the effect of an integrated approach involving the continuum of health system delivery on fetal or neonatal health outcomes [12]. In addition to studies mentioned in the introduction section, several other studies have also evaluated packages of interventions during pregnancy and postpartum periods, resulting in $30-40 \%$ reduction of neonatal mortality. A study in Pakistan that trained traditional birth attendants ensured provision of safe delivery kits and established a link of traditional birth attendants with back-up support to improve pregnancy and intrapartum care resulted in about $30 \%$ reduction of perinatal mortality [33]. Another Pakistan study by Jokhio et al. reported about $28 \%$ reduction in neonatal mortality and $35 \%$ reduction in stillbirth with lady health visitors who provided home-based newborn care with visits during pregnancy and post-partum periods [34]. These successful community intervention packages were conducted in settings with moderate to high levels of neonatal mortality (> 30 per 1000 live births) and stillbirth rates (> 30 per 1000 births) at baseline. The only study that evaluated a package of community-based intervention in an area with low level of neonatal mortality (<30 deaths/1000 live births) was in Mirzapur, Bangladesh; they reported no effect on perinatal mortality [15]. Considering the low rate of perinatal deaths at initiation of the integrated package (48/1000 births), the reduction in perinatal mortality observed in the present study is substantial and consistent with other studies mentioned above.

Table 5 Association of Perinatal Mortality with Intervention Periods, Before (2005-2006) and After (2008-2009) Intervention Implementation, by Service Area in Matlab, Bangladesh

\begin{tabular}{|c|c|c|c|c|}
\hline & Birth No. & Perinatal death No. (\%) & Odds ratio $(95 \% \mathrm{Cl})$ & Adjusted odds ratio* $(95 \% \mathrm{Cl})$ \\
\hline \multicolumn{5}{|c|}{ icddr, b Service Area } \\
\hline Beforet & 5354 & $257(4.8)$ & 1.00 & 1.00 \\
\hline After & 5305 & $168(3.2)$ & $0.65(0.53-0.79)$ & $0.64(0.52-0.78)$ \\
\hline \multicolumn{5}{|c|}{ Government Service Area } \\
\hline Beforet & 5291 & $309(5.8)$ & 1.00 & 1.00 \\
\hline After & 4816 & $269(5.6)$ & $0.95(0.81-1.13)$ & $0.88(0.74-1.04)$ \\
\hline
\end{tabular}

Cl: confidence interval

treference group

*Adjusted for women's age, parity, education, and asset index in quintiles 
Table 6 Cause Specific Early Neonatal Mortality Rate (death/1000 live births) During the Study Periods, Before (20052006) and After (2008-2009) Intervention Implementation, by Service Area in Matlab, Bangladesh

\begin{tabular}{|c|c|c|c|c|}
\hline \multirow[t]{2}{*}{ Causes of deaths } & \multicolumn{2}{|c|}{ icddr, b Service Area } & \multicolumn{2}{|l|}{ Govt. Service Area } \\
\hline & Before $\mathrm{n}$ (rate*) & After $n\left(\right.$ rate $\left.^{*}\right)$ & Before (Rate) n (rate*) & After (Rate) n (rate*) \\
\hline Asphyxia & $44(8.4)$ & $26(5.0)$ & $68(13.3)$ & $50(10.7)$ \\
\hline Infections & $13(2.5)$ & $6(1.5)$ & $12(2.3)$ & $17(3.6)$ \\
\hline Preterm/growth retarded & $20(3.8)$ & $21(4.0)$ & $31(6.0)$ & $31(6.6)$ \\
\hline Malformation & $5(1.0)$ & $9(1.7)$ & $1(0.2)$ & $1(0.2)$ \\
\hline Other causes & $26(5.0)$ & $8(1.5)$ & $32(6.2)$ & $21(5.0)$ \\
\hline Total & 108 & 70 & 144 & 120 \\
\hline
\end{tabular}

*per 1000 live births

Verbal autopsy data revealed that there was substantial decrease of birth-asphyxia, infection, and other-cause related mortality. However, birth asphyxia still remains a major contributor of neonatal death. Improving the quality of care as well as care seeking has limits; other factors that impact outcomes include the time and process of decision making at the home and facility levels which also need improvement. Although we have direct contact with the district/private clinic hospitals, there was limited influence over the decision making process to provide or use specific interventions in referral facilities. For example, prompt consent for cesarean section, arrangement of blood if needed, and absence of quality immediate post-natal care in the tertiary facility level may result in poor outcomes. Delays in referral from Matlab Hospital to district level facility may also occur, especially from the low-socioeconomic strata, and result in poor outcomes in district level facilities [42]. Strikingly, there was no reduction of mortality from preterm/ growth retarded deaths. This may indicate that the usual care (skin-to-skin contact) is not sufficient to improve outcomes for very preterm and/or low birth weight neonates. Further exploration is warranted to explain this finding.

The full package of intervention as shown in Figure 1 and more specifically the frequency of community interventions such as HBLSS visits, pregnancy home visits, post-natal home visits might be viewed by some as overambitious and challenging. However we believe that the infrastructure and human resources are in place in the government system that could implement a similar program. Under the current government health infrastructure and program, community health worker, Female Welfare Assistant (FWA), covers a population of about 5,000-6,000, and is to visit each household every 2 months and provides mainly family planning services. In addition, a Health Assistant (also equivalent to CHRW) is available for the same population to provide immunization from outreach clinics. Similarly, an icddr, b CHRW covers a population of about 2,700, with both family planning and immunization activities, and visits each household bimonthly. In the icddr, b SA CHRWs are also involved with ongoing studies on child and maternal health.

Since this study was carried out, the GoB has been implementing about 1,600 community clinics, each serving a 6,000 population with such services as immunization, family planning, ANC and treatment of minor illnesses, through a FWA. Prior to this new GoB program, the lowest GoB facilities were Health and Family Welfare Centers (union sub-centers covering a population of about 25,000 each) staffed by one nurse-midwife offering ANC and delivery care of pregnant women, similar to the icddr, b sub-centers. Also, the evidencebased practices during the continuum of pregnancy and post-partum periods may be readily adopted in the government sub-district level hospital as we did in the Matlab hospital. Therefore, it is not a matter that the government program lacking infrastructure or human resources but rather inadequate linkage among health care providers at different levels as well as a lack of monitoring program and effective supervision of health workers, and also inadequate knowledge about evidencebased interventions.

\section{Conclusion}

We observed a significant reduction of perinatal mortality over a short period of time in an area of low level of mortality at baseline. The findings are robust even after adjusting for socio-demographic factors, although the possibility of residual confounding cannot be ruled out completely. We believe that the improvement in perinatal survival most likely resulted from the integration of evidence-based interventions provided over the continuum of care from pregnancy through the postpartum period. Monitoring the process and outcome indicators in "real time" including quality assurance at all level of community and basic emergency obstetric care services was also crucial. In conclusion, we showed the continuum of care approach provided through the integration of service delivery modes decreased the perinatal mortality rate within a short period of time. We recommend 
further testing of this model within the government health system in Bangladesh and other developing countries urgently to identify the model that can be readily replicable in the local health system in the respective country to achieve the MDG 4.

\section{Abbreviations}

ANC: Antenatal care; CHRWs: Community health research workers; Cl: Confidence interval; GoB: Government of Bangladesh; HBLSS: Home based life saving skills; HDSS: Health and demographic surveillance system; icddr, b: International Centre for Diarrhoeal Disease Research: Bangladesh; OR: Odds ratio; MCH-FP: Maternal: child health and family planning; MDG: Millennium development goal; MNCH: Maternal, neonatal and child health; SA: Service area.

\section{Acknowledgements and funding}

We acknowledge the contribution of Drs. Al-Fazal Khan, Chandra Shakhar Das, Rowshan Jahan, and Rafia Akhter for implementation of MNCH study. Dr. Kamal K Biswas for contributing initial set up of the study, facilitating training activities and also developing guidelines and manuals for $\mathrm{MNCH}$ project.

This research study was funded by icddr, $\mathrm{b}$ and its donors which provide unrestricted support to icddr, b for its operations and research. Current donors providing unrestricted support include: Australian Agency for International Development (AusAID), Government of the People's Republic of Bangladesh; Canadian International Development Agency (CIDA), Swedish International Development Cooperation Agency (Sida), and the Department for International Development, UK (DFID). We gratefully acknowledge these donors for their support and commitment to icddr, b's research efforts.

\section{Author details}

${ }^{1}$ Centre for Reproductive Health, icddr,b, Mohakhali, Dhaka 1212, Bangladesh. ${ }^{2}$ School of Human Evolution and Social Change, Arizona State University, P. O. Box 872402, Tempe, AZ 85287-2402, USA. ${ }^{3}$ Emory University, 1520 Clifton Road, NE, Atlanta, GA 30322-4027, USA. ${ }^{4}$ John Snow Inc, 1776 Massachusetts Avenue, Suite 300, Washington, DC, USA.

\section{Authors' contributions}

$A R, A M, L S, M Y, P K S, S E A, A B$ and MK contributed to the study concept and design. AR, JP, Aminur R, HB, HR, AM, and MY supervised implementation of the study. AR, MR, PKS coordinated collection of field data. AR, JP, MR, AM and DH contributed initial data cleaning and analyses. All authors participated in the data analysis and reporting stage, and have seen and approved the final draft of the report.

\section{Competing interests}

The authors declare that they have no competing interests.

Received: 15 August 2011 Accepted: 10 December 2011

Published: 10 December 2011

\section{References}

1. Diallo AH, Meda N, Zabsonre E, Sommerfelt H, Cousens S, Tylleskar T: Perinatal mortality in rural Burkina Faso: a prospective community-based cohort study. BMC Pregnancy Childbirth 10:45.

2. World Health Organization: Neonatal and perinatal mortality: country, regional and global estimates. WHO Publications Geneva: WHO; 2006, 69.

3. Zupan J: Perinatal mortality in developing countries. N Engl J Med 2005, 352(20):2047-2048.

4. WHO: Countdown to 2015 Decade Report (2000-2010): Taking Stock of Maternal, Newborn and Child Survival World Health Organization; 2010

5. Bhutta ZA, Darmstadt GL, Hasan BS, Haws RA: Community-based interventions for improving perinatal and neonatal health outcomes in developing countries: a review of the evidence. Pediatrics 2005, 115(2 Suppl):519-617.
6. Lawn JE, Blencowe H, Pattinson R, Cousens S, Kumar R, Ibiebele I, Gardosi J, Day LT, Stanton C: Stillbirths: where? when? why? how to make the data count? Lancet 377(9775):1448-1463.

7. Lawn JE, Lee AC, Kinney M, Sibley L, Carlo WA, Paul VK, Pattinson R, Darmstadt GL: Two million intrapartum-related stillbirths and neonatal deaths: where, why, and what can be done? Int I Gynaecol Obstet 2009, 107(Suppl 1):S5-S19.

8. Lawn JE, Yakoob MY, Haws RA, Soomro T, Darmstadt GL, Bhutta ZA: 3.2 million stillbirths: epidemiology and overview of the evidence review. BMC Pregnancy Childbirth 2009, 9(Suppl 1):S2.

9. Say L, Donner A, Gulmezoglu AM, Taljaard M, Piaggio G: The prevalence of stillbirths: a systematic review. Reprod Health 2006, 3:1.

10. WHO: World Health Statistics, 2010 Geneva: World Health Organization; 2010.

11. Bahl R, Qazi S, Darmstadt GL, Martines J: Why is continuum of care from home to health facilities essential to improve perinatal survival? Semin Perinatol 34(6):477-485.

12. Kerber KJ, de Graft-Johnson JE, Bhutta ZA, Okong P, Starrs A, Lawn JE: Continuum of care for maternal, newborn, and child health: from slogan to service delivery. Lancet 2007, 370(9595):1358-1369.

13. Bang AT, Reddy HM, Deshmukh MD, Baitule SB, Bang RA: Neonatal and infant mortality in the 10 years (1993-2003) of the Gadchiroli field trial: effect of home-based neonatal care. J Perinatol 2005, 25(Suppl 1):S92-107.

14. Baqui AH, El-Arifeen S, Darmstadt GL, Ahmed S, Williams EK, Seraji HR, Mannan I, Rahman SM, Shah R, Saha SK, et al: Effect of community-based newborn-care intervention package implemented through two servicedelivery strategies in Sylhet district, Bangladesh: a cluster-randomised controlled trial. Lancet 2008, 371(9628):1936-1944.

15. Darmstadt GL, Choi Y, Arifeen SE, Bari S, Rahman SM, Mannan I, Seraji HR, Winch PJ, Saha SK, Ahmed AS, et al: Evaluation of a cluster-randomized controlled trial of a package of community-based maternal and newborn interventions in Mirzapur, Bangladesh. PLoS One 5(3):e9696.

16. Manandhar DS, Osrin D, Shrestha BP, Mesko N, Morrison J, Tumbahangphe KM, Tamang S, Thapa S, Shrestha D, Thapa B, et al: Effect of a participatory intervention with women's groups on birth outcomes in Nepal: cluster-randomised controlled trial. Lancet 2004, 364(9438):970-979

17. Kumar V, Mohanty S, Kumar A, Misra RP, Santosham M, Awasthi S, Baqui AH, Singh P, Singh V, Ahuja RC, et al: Effect of community-based behaviour change management on neonatal mortality in Shivgarh, Uttar Pradesh, India: a cluster-randomised controlled trial. Lancet 2008, 372(9644):1151-1162.

18. Azad K, Barnett S, Banerjee B, Shaha S, Khan K, Rego AR, Barua S, Flatman D, Pagel C, Prost A, et al: Effect of scaling up women's groups on birth outcomes in three rural districts in Bangladesh: a clusterrandomised controlled trial. Lancet 375(9721):1193-1202.

19. Darmstadt GL: Global perinatal health: accelerating progress through innovations, interactions, and interconnections. Semin Perinatol 34(6):367-370.

20. Darmstadt GL, Walker N, Lawn JE, Bhutta ZA, Haws RA, Cousens S: Saving newborn lives in Asia and Africa: cost and impact of phased scale-up of interventions within the continuum of care. Health Policy Plan 2008, 23(2):101-117.

21. WHO: Integrated Management of Pregnancy and Childbirth. Pregnancy, Childbirth, Postpartum and Neonatal Care: A Guide for Essential Practice World Health Organization; 2006.

22. Buffington S, Sibley L, Beck D, Armbruster D: Home Based Life Saving Skills. Washington, DC: American College of Nurse Midwives; 12004.

23. Sibley L, Buffington ST, Tedessa L, MCNatt K: Home-based life saving skills in Ethiopia: an update on the second phase of field testing. J Midwifery Womens Health 2006, 51(4):284-291.

24. Dynes M, Rahman A, Beck D, Moran A, Pervin J, Yunus M, Rashid MH, Gazi T, Kanti Biswas K, Buffington $S$, et al: Home-based life saving skills in Matlab, Bangladesh: a process evaluation of a community-based maternal child health programme. Midwifery 27(1):15-22.

25. National Institute of Population Research and Training (NIPORT), Mitra and Associates, and Macro International: Bangladesh Demographic and Health Survey 2007 Dhaka, Bangladesh and Calverton, Maryland: National Institute of Population Research and Training, Mitra and Associates, and Macro International; 2009. 
26. Ahmed S, Khan MM: A maternal health voucher scheme: what have we learned from the demand-side financing scheme in Bangladesh? Health Policy Plan 26(1):25-32.

27. Baqui AH, Black RE, Arifeen SE, Hill K, Mitra SN, al Sabir A: Causes of childhood deaths in Bangladesh: results of a nationwide verbal autopsy study. Bull World Health Organ 1998, 76(2):161-171.

28. Gwatkin DR, Rustein S, Johnson K, Pande RP, Wagstaff A: Socio-economic differences in health nutrition and population in Bangladesh. Washington, DC: The World Bank; 2000 [http://siteresources.worldbank.org/ INTPAH/Resources/Publications/Country-Reports/bangladesh.pdf], accessed 21 November 2010.

29. Ronsmans C, Vanneste AM, Chakraborty J, van Ginneken J: Decline in maternal mortality in Matlab, Bangladesh: a cautionary tale. Lancet 1997, 350(9094):1810-1814.

30. Ronsmans C, Chowdhury ME, Alam N, Koblinsky M, El Arifeen S: Trends in stillbirths, early and late neonatal mortality in rural Bangladesh: the role of public health interventions. Paediatr Perinat Epidemiol 2008, 22(3):269-279.

31. Bangladesh Maternal Mortality and Health Care Survey 2010: Summary of key findings and implications [http://www.dghs.gov.bd/dmdocuments/ bmms_2010_summary.pdf], accessed in July 12, 2011.

32. Brown CA, Sohani SB, Khan K, Lilford R, Mukhwana W: Antenatal care and perinatal outcomes in Kwale district, Kenya. BMC Pregnancy Childbirth 2008, 8:2.

33. Bhutta ZA, Memon ZA, Soofi S, Salat MS, Cousens S, Martines J: Implementing community-based perinatal care: results from a pilot study in rural Pakistan. Bull World Health Organ 2008, 86(6):452-459.

34. Jokhio AH, Winter HR, Cheng KK: An intervention involving traditional birth attendants and perinatal and maternal mortality in Pakistan. N Engl J Med 2005, 352(20):2091-2099.

35. Crowley P: Prophylactic corticosteroids for preterm birth. Cochrane Database Syst Rev 2000, 2-CD000065.

36. Kenyon S, Pike K, Jones DR, Brocklehurst P, Marlow N, Salt A, Taylor DJ: Childhood outcomes after prescription of antibiotics to pregnant women with spontaneous preterm labour: 7-year follow-up of the ORACLE II trial. Lancet 2008, 372(9646):1319-1327.

37. Gulmezoglu AM, Crowther CA, Middleton P: Induction of labour for improving birth outcomes for women at or beyond term. Cochrane Database Syst Rev 2006, , 4: CD004945.

38. Worku B, Kassie A: Kangaroo mother care: a randomized controlled trial on effectiveness of early kangaroo mother care for the low birthweight infants in Addis Ababa, Ethiopia. J Trop Pediatr 2005, 51(2):93-97.

39. Suman RP, Udani R, Nanavati R: Kangaroo mother care for low birth weight infants: a randomized controlled trial. Indian Pediatr 2008, 45(1):17-23.

40. Victora CG: Effect of breastfeeding on infant and child mortality due to infectious diseases in less developed countries: a pooled analysis. WHO collaborative study team on the role of breastfeeding on the prevention of infant mortality. Lancet 2000, 2355(9202):451-5.

41. Baqui AH, Ahmed S, El Arifeen S, Darmstadt GL, Rosecrans AM, Mannan I, Rahman SM, Begum N, Mahmud AB, Seraji HR, et al: Effect of timing of first postnatal care home visit on neonatal mortality in Bangladesh: a observational cohort study. BMJ 2009, 339:b2826.

42. Ronsmans C, Chowdhury ME, Koblinsky M, Ahmed A: Care seeking at time of childbirth, and maternal and perinatal mortality in Matlab, Bangladesh. Bull World Health Organ 2010, 88(4):289-296.

\section{Pre-publication history}

The pre-publication history for this paper can be accessed here: http://www.biomedcentral.com/1471-2458/11/914/prepub

\section{doi:10.1186/1471-2458-11-914}

Cite this article as: Rahman et al: Effectiveness of an integrated approach to reduce perinatal mortality: recent experiences from Matlab, Bangladesh. BMC Public Health 2011 11:914.

\section{Submit your next manuscript to BioMed Central and take full advantage of:}

- Convenient online submission

- Thorough peer review

- No space constraints or color figure charges

- Immediate publication on acceptance

- Inclusion in PubMed, CAS, Scopus and Google Scholar

- Research which is freely available for redistribution

Submit your manuscript at www.biomedcentral.com/submit
C Biomed Central 